discover the physical cause of anger, of hate, and of sensuality. The brain of the man of cool and deliberate action must differ in its intimate physical elements from the brain of the man whose outbursts of passion are notorious, and whose actions are the results of impulses that are often beyond the control of the will. By patient inquiry in practical medicine, pathology, and morbid anatomy, much may be done in the direction of referring each phase of morbid mental action to its physical cause-to some hereditary defect or material change of structure that time and habit have effected. In the case of Henry Patrick there must of necessity be some deviation from the normal structure, some radical defect that interferes at stated periods with the natural morement, not only of the brain, but of the whole nervous machinery by which thought, speech, and action are maintained and directed. The answer to the question as to whether this man should or should not be held responsible for his acts ought not, in my opinion, to depend upon his every-day conduct, but upon a strict investigation into the facts of the disease from which he suffers. This may have already been made. I think, however, it should be laid down as a rule that no man who suffers from a disease which clearly and without doubt implies that his brain is more or less damaged should be held responsible for his acts.

I am, Sir, yours truly

Bath-street, Glasgow, Dec. 21st, 1885. ROBERT MACPHERSON.

\section{THE GOVERNMENT OF THE COLLEGE OF SURGEONS.}

To the Editor of THE LANCET.

SIR,-As a Member of the Royal College of Surgeons, an disconnected with either the Press or the Society of Members of the Royal College of Surgeons, I should like to make a few remarks respecting the meeting of the Fellows and Members on the 17th ult. First, respecting the charge made by Mr. Brudenell Carter, that the meetings were the outcome of agitations of the Medical Press, I will only say that this statement was distinctly and emphatically refuted at the meeting; and if this refutation is insufficient, I am quite sure the Medical Press is strong enough for its own protection. Secondly, it has been stated by a writer in your journal that when a man takes the Membership of the Royal College of Surgeons of England he pays the fees for the diploma only, and has no more right to a voice in the government of the College than he has in indicating how his butcher or baker should conduct business. This idea is rather crude. But I will endeavour to refute it. If the butcher or baker be a man of respectability, every customer has a distinct voice as to the manner in which business shall be conducted, for if the business is not managed to the satisfaction of the customer, he at once withdraws his patronage and deals elsewhere. Again, when the butcher or baker sells so much meat or bread, the customer is at liberty to deal with it precisely as he pleases. Now, in the case of the diploma of the Royal College of Surgeons there is no analogy. For once a Member, and you are then a Member or Fellow for life, and the College very properly reserves the right of supervising your conduct and the manner in which you degrade or elevate its diploma. Now, if a man can degrade his college, surely he has an equal right to elevate it. Hence it follows that the College clearly recognises the power of its Members to degrade or elevate the College by the manner in which its individual Members conduct business. Deep degradation is usually visited with severe and speedy punishment, frequently too severe. But there are an infinite number of minor ways in which the College is degraded every day, such as shielding unqualified persons, retailing professional skill (?) for sixpence, keeping open retail establishments, making a charge for seeing the poor and needy at our hospitals, and this, too, by those who should set a higher and brighter example, and many other matters which are beneath the notice of the College; all of which minor offences do more to degrade the College and to undermine the position of its individual members than do some of the more serious offences which are usually risited with the rigour of the law. On the other hand, members who elevate the College all over the world by their own personal skill and indomitable perseverance are too frequently passed by without either recognition or reward.
Thirdly, Mr. Rivington hit the right nail when he diploma lay, when the College charged several guineas more for its diploma than do other colleges which convey equal rights and privileges, and often, I may add, superior advantages. Nowadays the value of a thing depends on how much the article will fetch in the open market. It is a notorious fact that a man from over the Border with a double diploma, costing less than the single diploma of the Royal College of Surgeons, which most unjustly entailed a double examination, can command better and more remunerative appointments. And further, without the consent of the Members of the College the Royal College of Surgeons has now combined with the Royal College of Physicians to grant a double diploma, and they seek also to confer the degree of M.D. upon those of their Members who have obtained their conjoint diploma thereby excluding the 15,000 or 16,000 Members who have already passed the examinations of the College, not only in surgery, but many of them in medicine also. In case the combined Colleges ever obtain the powers to grant the degree of M.D. to their examinees, the time is not far distant when a Member of the Royal College of Surgeons will be practically and legally unqualified. A far more graceful act on the part of the combined Colleges would have been to have conferred the diplomas of the Conjoint Board upon all of the Members of the Royal College of Surgeons or Licentiates of the Royal College of Physicians who could produce evidence of having passed a satisfactory and complete examination in medicine, surgery, and midwifery, such diploma to be conferred without further fee or examination.

I am not one of those who would seek in any way to lower the standard of examinations or the qualifications required for the sweets of office, but the contrary. I would have but one high standard of examination, one fee, and one portal of admission to the profession for each division of the kingdom, and by such means do away with most of those petty jealousies and annoyances which one so constantly hears of, such as, "He is not a regular doctor," or " He's more than a doctor, he's a physician," \&c. After all, Mr. Editor, it is not colleges nor universities of universities which make men, but it is men who make colleges, aye, and universities too, all that they ever are, ever were, or ever will be. I am, Sir, yours truly,

Kennington-park, Dec. 21st, 1885. $\quad$ ALBERT S. MoRTON.

\section{"DISEASED MEAT"}

To the Editor of THE LANCET.

SIR,-In reply to Professor Walley, of the Royal Veterinary College, Edinburgh, I may say that my authority for the statement that domestic animals produce no sputum is Koch, who says: " Die Thiere produciren bekanntlich kein Sputum, so dass von ihnen während des Lebens aus dem Respirationswegen keine Tuberkubacillen ins Freir geliefert werden." And though I fully recognise the truth of Professor Walley's remarks, I still think that the excreta of domestic animals piay a very small part in spreading tuberculosis among human beings. Professor Walley is, of course, specially qualified to speak with authority as to the frequency of tubercular mammitis in cattle. I had not seen Professor Bang's article, and I based my opinion on the statement of Koch :" " Da aber Perlsuchtknoten im Enter nicht sehr oft vorkommen." I may also mention that one of the leading veterinary surgeons of this town has for the past year been looking out for a case of tubercular disease of the udder, and has hitherto failed to meet with an undoubted one, though he frequently finds tuberculosis of other organs. I am therefore driven to the conclusion either that tubercular disease of the udder is not very common, or that a capable reterinary surgeon may fail to recognise it. It is not without significance in this connexion that tubercular disease of the human mamma is a very rare affection. Sir Astley Cooper, I believe, described a scrofulous disease of the breast, but I have not been able to refer to his original description. I can find no reference to tubercle of the mamma in the last edition of Holmes' "System of Surgery." In Cornil and Ranvier's "Pathological Histology" ${ }^{3}$ the passage occurs: "We know of no example of tubercles occurring in

1 Koch: Die Etiologie der Tuberculose. Mittheilüngen aus dem Kaiserlichen Gesundheitsamte. Berlin, I881, p. 81.

Ib., p. 82 .

English edition, translated by Shakespeare and Simes, 1880, p. 710 
the mammary gland." Paynet says: "Tubercle has not been observed to occur in the breast."

While remaining of the opinion that tubercle bacilli and their spores may, and frequently do, pass tbrough a healthy alimentary canal without producing disease, I still recognise (especially since the report of Drs. Klein and Heneage Gibbes' experimen's ${ }^{5}$ ) that the consumption of tubercular flesh involves a risk to which the public ought not to be exposed; and I am only too glad to add my roice to that of Professor Walley in asking for further legislation regarding the sale of milk, and for a more efficient system of meat inspection. The latter will never be attained until public abattoirs are provided in all towns and the numerous and scattered slaughterhouses are abolished.

Nottingham, Dee. 2:rd, 1835 . am, Sir, yours truly,

\section{A N A TO MI C A L A NO M A L IES. To the Editor of THE LANCET.}

SrR,-In THE LANCET of the 19th inst. your Dublin correspondent notes an instance of a rare irregularity of the vertebral artery-namely, that in which it springs from the transverse part of the arch of the aorta. I have seen three cases of this within the last twelve months in the dissectingroom of Trinity College, the abnormality in each instance occurring in connexion with the left vertebral.

It may, perhaps, not be uninteresting to your readers if I should mention two very rare nervous anomalies which I had the good fortune to come across of late. The first was a case in which the communicans noni arose from the pneumogastric, and may probably be explained by the fact that the branch of communication between the second cervical nerve and the pneumogastric was unusually large. The descendens noni is not unfrequently found arising from the latter, but it is very rare for the communicans to do likewise.

The second is an anomaly which, so far as I am aware, has not been observed before. The nerve to the rhomboids, which arises from the fifth cervical, gave off a slender branch, descended behind the brachial plexus, and supplied the upper digitations of the serratus magnus muscle. As the rhomboid nerve usually gives one or two branches to the Ievator anguli scapulæ, the above abnormality derives special interest from the fact that in certain of the lower animals the serratus magnus and levator anguli scapulæ form one continuous muscle, the portion which is deficient in man being supplied by slips from the three lowest cervical vertebræ. $1 \mathrm{am}$, Sir, your obedient servant, JOHN P. HENRY, B.A.,

Dublin, Dec. 21st, 1885. Assistant Demonstrator of Anatomy, T.C.D.

\section{"ARTHRECTOMY."}

To the Editor of THE LANCET.

SrR.-I notice in THE LANCET of December 26th a remark of Mr. Mayo Robson's, at the Leeds Medico-Chirurgical Society, in a discussion upon so-called "arthrectomy" of the knee. He states that, according to reports of mine, erasion, as I prefer to call it, succeeded only once in sixteen cases. As I think the operation in suitable cases a valuable one, I desire to correct this statement. In only one instance was a perfect and movable joint preserved, but in five other cases a sound though stiff limb resulted, and two more have since healed: making eight cases in which a result was obtained as good as excision in other ways, and better, in that there is an absence of shortening from removal of bone. These limbs are very difficult to keep straight among the poorer classes; but the same objection applies to excision in young children, and it is as a substitute for excision that I hare brought my cases forward. I claim that half my erasions have been successful, and in suitable cases the percentage will, I believe, be much greater in the future. My notes were published in the Medical Chronicle for July, 1885. I am, Sir, yours faithfully, Manchester, Dec. 29th, 1885. G. A. WrIGHT.

4 Jones and Siereking's Pathological Anatomy, edited by Payne, 1875, p. 788 . 5 Report of the Local Gorernment Board, and THE LANCET, Nor. 2sth,
1885, p. 1015 .

\section{(From our own Correspondent.)}

LITERPOOL.

DEPRESSION OF TRADE AND THE MEDICAL CHARITIES.

THE long-continued depression of trade and commerce has had a very serious effect upon the finances of our local medical charities. The Eye and Ear Infirmary, though most economically conducted, is sexiously crippled in consequence of its diminished income, and an urgent appeal has been issued to the public. The same observation applies, with some modification, to all the hospitals, and especially the Royal Southern Hospital.

THE MAYOR AND CHRISTMAS DINNERS.

Alderman David Radcliffe, the re-elected mayor, is repeating the noble munificence he showed last year. One thousand hot pots, each sufficient for a large family, are to be distributed by him, together with three hundred more contributed by friends. These will be given through the Rev. Messrs. Lester and Postance, Father Nugent, and H. G. Brown. Other seasonable gifts will probably follow.

RECENT CASES AT THE CITY CORONER'S COURT.

An inquest was held on the body of a female infant twelve days old, which had died while under the care of a midwife with symptoms of opium poisoning. She was the illegitimate daughter of a widow residing at a distance from Liverpool, and was sent to the midwife to be nursed. This was accomplished, according to her own admission, by feeding it with boiled arrowroot mixed with milk, and, because the child was a very cross one, giving it a drop of laudanum on a piece of sugar. Dr. Leigh, who was called in to see the child, and who subsequently made a post-mortem examination, gave it as his opinion that death resulted from laudanum poisoning. The jury returned a verdict of "Death by misadventure," and censured the mother of the child, as well as the midwife, for their conduct. On the same day, an inquest was held on the body of a newly born male child, found in the coal cellar of a temperance hotel in the north part of the city. A young woman, who had been a domestic servant in the hotel, had been committed for trial on a charge of concealing the birth of an infant whose decomposed body had been found in her box. She had been observed to show signs of advanced pregnancy, and about the 10th ult. there were appearances indicating that she had been recently delivered. On the 1st inst., after her committal, the body of the deceased was found in the coal cellar by the servant who took her place. It was fully matured, and had a man's necktie tightly tied round its neck. It was examined by Dr. Wilde, the resident surgeon at the North Dispensary, and subsequently by Mr. F.T. Paul, lecturer on medical jurisprudence, and Mr. F. W. Lowndes, surgeon to the police. From the condition of the funis, the terminal end of which was in a dry, gangrenous state, and the state of the lungs and heart, it was clear that the child had survived its birth some hours; and the appearances of the neck, mouth, and tongue pointed to strangulation as the cause of death. A verdict of "Wilful murder" was returned against the servant.

\section{HEAXTH OF LIVERPOOL.}

At the last meeting of the Health Committee on the 17th inst., the medical officer (Dr. Stopford Taylor) reported that the death-rate was equal to 24.5 per 1000 of the estimated population. There were 2 deaths from small-pox (one vaccinated and one unraccinated), 14 from measles, 4 from scarlatina, and 4 from fever. Theinquestcases amounted to 17 , of which 2 were due to excessive drinking and 3 (under one year of age) to suffocation. The number of uncertified deaths was 11. There were also reported to the medical officer 9 cases of fever, 6 cases of small-pox, and 33 cases of scarlatina. There were on the 17 th inst. 50 cases of smallpox in the city hospital.

LADIES' CHARITY AND LYING-IN HOSPITAL.

A bazaar was recently held in aid of this charity, and resulted in the handsome balance of $£ 159 \pm$ (after all expenses had been paid) for the building fund. The charity is doing a very useful work among the poor at this inclement season, and deserves every encouragement. By its means poor married women are provided with skilled attendance in their confinements, with certain medical and other comforts, and skilled obstetric assistance in difficult 